\title{
Morfologia e variações anatômicas dos ventres frontais do músculo occipitofrontal: estudo anatômico e classificação
}

\author{
Morphology and anatomical variations of the frontal bundles from the \\ occipitofrontal muscle: anatomical study and classification
}

\author{
Norton GLATTSTEIN ${ }^{1}$ \\ ELÓdia Avila ${ }^{2}$ \\ Santiago Sosa Henriquez ${ }^{3}$ \\ Cristina Destro ${ }^{4}$
}

Trabalho realizado no Instituto de Cirurgia Plástica Santa Cruz, São Paulo, SP, Brasil.

Artigo submetido pelo SGP (Sistema de Gestão de Publicações) da RBCP.

Artigo recebido: $15 / 12 / 2009$ Artigo aceito: 2/8/2010

\begin{abstract}
RESUMO
Introdução: Com o desenvolvimento dos retalhos musculares, miocutâneos, osteomiocutâneos, microcirúrgicos e os novos procedimentos estéticos sobre o músculo occipitofrontal, tornou-se essencial o conhecimento anatômico desta região. Estudamos neste trabalho a morfologia detalhada dos ventres frontais e suas variações anatômicas, para que possam servir como pontos de referência úteis em cirurgias reparadoras e estéticas. Método: Foram estudados 56 cadáveres não fixados, 35 homens e 21 mulheres, 37 de raça branca e 19 nãobranca, com idade variando de 19 a 85 anos. Neste material foram dissecados 112 ventres musculares. Resultados: Os dados obtidos foram colocados em tabelas, seguindo-se os parâmetros de sexo, idade, raça, distâncias interventrais, larguras, alturas e espessuras dos ventres frontais bilateralmente. As larguras, espessuras e distâncias interventrais foram medidas a $1,5,3,0$ e $4,5 \mathrm{~cm}$ da glabela, em ambos os ventres. Os ventres frontais apresentaram-se de maneiras diferentes, principalmente quanto à disposição das fibras mediais, sendo agrupados em 4 tipos. Conclusões: $\mathrm{O}$ amplo conhecimento anatômico nos permite um planejamento pré-operatório mais seguro.
\end{abstract}

Descritores: Face/anatomia \& histologia. Músculos faciais. Cirurgia Plástica/métodos.

\section{SUMMARY}

Introduction: The development of muscles, myocutaneous, osteomiocutaneous, and the variety of microsurgical flaps, added to the new aesthetic procedures on frontal bellies, became essential the well knowledge of this region. The studied in this paper covered the detailed morphology of the frontal and their anatomical variations, that can serve as useful reference points in reparative and cosmetic surgery. Methods: We studied 56 non-fixed cadavers, 35 men and 21 women, 37 white and 19 non-white, with age ranging from 19 to 85 years old. In this material, 112 muscles were dissected. Results: Data were available in tables followed by the parameters of sex, age, race, interventricular distances, heights and widths of the frontal bilaterally. The widths, thickness and interventricular distances were measured at $1.5,3.0$ and $4.5 \mathrm{~cm}$ from the glabella in both wombs. The frontal were presented in different ways, especially regarding the disposition of the medial and were grouped into four types. Conclusion: The extensive anatomical knowledge allows us to a preoperative planning safer

Descriptors: Face/anatomy \& histology. Facial muscles. Plastic Surgery/methods.

1. Membro titular da Sociedade Brasileira de Cirurgia Plástica; Assistente do Instituto de Cirurgia Plástica Santa Cruz.

2. Membro associado da Sociedade Brasileira de Cirurgia Plástica; Cirurgiã Plástica.

3. Membro da Sociedade de Cirurgia Plástica da Venezuela; Cirurgião Plástico.

4. Residente do Instituto de Cirurgia Plástica Santa Cruz; Residente de Cirurgia Plástica. 


\section{INTRODUÇÃO}

Várias abordagens cirúrgicas sobre os ventres frontais do músculo occipitofrontal têm sido descritas na literatura. Com o desenvolvimento dos retalhos musculares, miocutâneos, osteomiocutâneos, microcirúrgicos e os novos procedimentos estéticos sobre esta região, tornou-se essencial o conhecimento anatômico da mesma.

A anatomia clássica descreve o músculo occipitofrontal, juntamente com o músculo temporoparietal, como constituintes de um músculo ainda maior, responsável pela movimentação do couro cabeludo, o músculo epicrânio ou músculo do escalpe ${ }^{1-4}$.

O músculo occipitofrontal é largo, músculo-fibroso e cobre o dômus do crânio desde a linha nucal, onde se inserem os dois ventres occipitais, até o supercílio onde terminam os ventres frontais, também em número de dois. É constituído, portanto, por 4 partes, duas frontais e duas occipitais, conectados pela gálea aponeurótica ${ }^{5}$.

Os ventres frontais do músculo occipitofrontal são bilaterais, quadriláteros, finos e aderentes à fáscia superficial. São geralmente mais largos do que os ventres occipitais e suas fibras são mais longas e próximas.

Superiormente se inicia na gálea aponeurótica, inferiormente suas fibras mediais continuam com as do músculo prócero e suas fibras médias se misturam com as dos músculos corrugadores do supercílio e músculos orbiculares. Não possuem inserções ósseas, inserindo-se à derme nos rebordos orbitários superiores ${ }^{6}$. Suas fibras laterais se imbricam também com as dos músculos orbiculares até o processo zigomático do osso frontal. As margens mediais caminham juntas por certa distância acima da implantação do nariz.

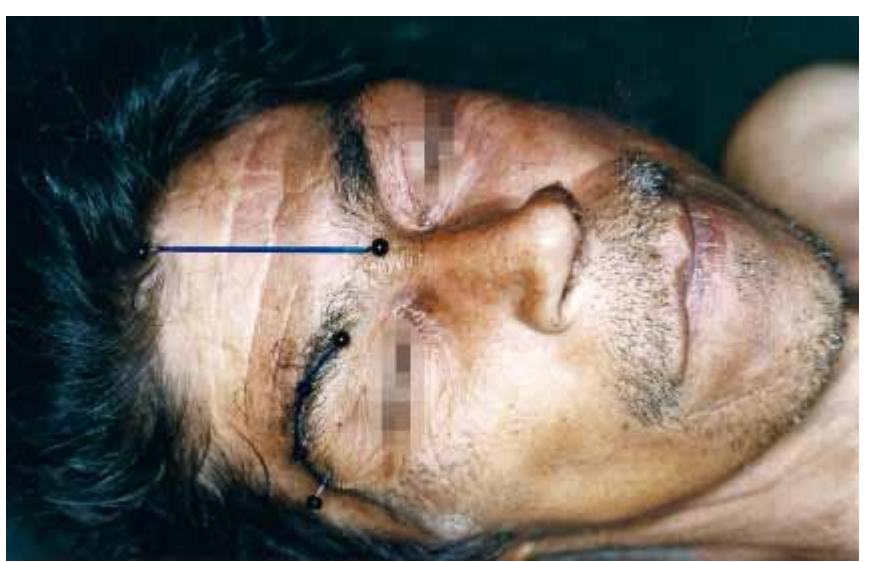

Figura 1 - Cadáver em decúbito dorsal horizontal. Marcação externa dos rebordos orbitários superiores, trichion e glabela.
Os ventres frontais agem elevando a parte superior dos supercílios e a pele sobre a implantação do nariz, tracionando o escalpe para frente através da fronte até as linhas frontais horizontais. É um músculo que transmite expressões, como surpresa.

A irrigação se faz por meio das artérias supraorbitárias, supratrocleares e ramos da artéria temporal superficial.

Sua inervação motora deriva dos ramos temporais do nervo facial, a a sensitiva dos ramos frontais (supraorbital e supratroclear) do nervo oftálmico, divisão do trigêmio ${ }^{7}$.

Estudamos, neste trabalho, a morfologia detalhada dos ventres frontais e suas variações anatômicas, para que possam servir como pontos de referência úteis em cirurgias reparadoras e estéticas.

\section{MÉTODO}

Foram estudados 56 cadáveres não fixados, 35 homens e 21 mulheres, 37 de raça branca e 19 não-branca, com idade variando de 19 a 85 anos. Na raça não-branca, foram incluídos os cadáveres mestiços, negros e um cadáver de raça amarela. Neste material foram dissecados 112 ventres musculares.

Todos possuíam 24 horas de óbito ou menos, provenientes do Serviço de Verificação de Óbito do Hospital das Clínicas de São Paulo. Nenhum dos casos apresentava trauma cranioencefálico ou lesões faciais de qualquer espécie.

Com o cadáver em decúbito dorsal horizontal, procediase às marcações externas de dois pontos antropométricos descritos por Ávila ${ }^{8}$ glabela (ponto entre os dois arcos superciliares) e trichion (ponto que marca o início da linha capilar anterior), além dos rebordos orbitários superiores (Figura 1).

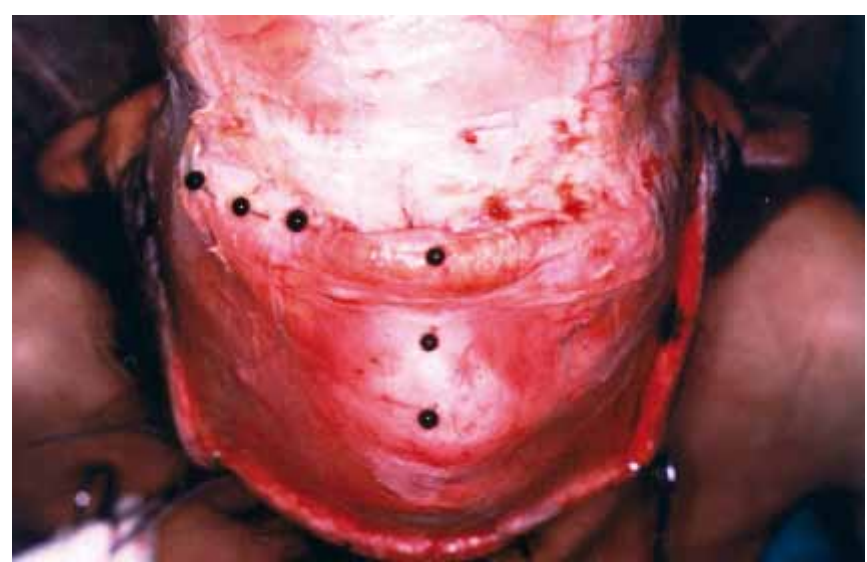

Figura 2 - Retalho frontal rebatido: pontos externos marcados na face interna do retalho frontal. 


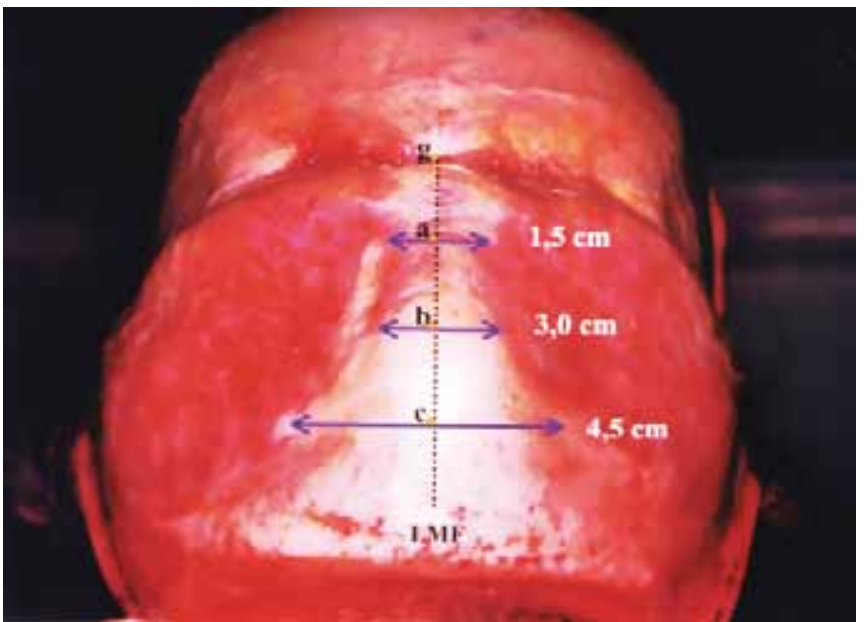

Figura 3 - Vista anterior: retalho frontal rebatido, linha médiofrontal demarcada (LMF), medições das larguras e espessuras ventrais a 1,5, 3,0 e 4,5 cm do ponto glabelar.

Procedia-se a uma incisão coronal bilateral extensa, subgaleal, descendo até as regiões retroauriculares. Prosseguia-se dissecando anteriormente ao mesmo nível, até os rebordos orbitários superiores.

As marcações externas dos pontos acima descritos eram então transferidas para a face interna do retalho, delimitando as linhas médio-frontal e orbitárias (Figura 2).

Nesta linha vertical médio frontal, foram estabelecidos três pontos de referência a $1,5,3,0$, e $4,5 \mathrm{~cm}$ a partir da glabela, em sentido superior (Figura 3 ).

Nestes pontos, as medições das larguras e espessuras bilateralmente foram realizadas, assim como as distâncias interventrais. As alturas ventrais foram obtidas traçando-se uma linha paralela ao trajeto dos feixes nervosos supraorbitários (Figura 4).

As espessuras foram medidas com o uso de paquímetro, após dissecção do músculo nos pontos assinalados.

O estudo foi aprovado pelo Comitê de Ética do Hospital das Clínicas de São Paulo.

\section{RESULTADOS}

Os dados obtidos foram colocados em tabelas seguindose os parâmetros de sexo, idade, raça, distâncias interventrais, larguras, alturas e espessuras dos ventres frontais bilateralmente. As larguras, espessuras e distâncias interventrais foram medidas a 1,$5 ; 3,0$ e $4,5 \mathrm{~cm}$ da glabela em ambos os ventres.

Os dados foram então submetidos a análise estatística, estabelecendo-se a média e o desvio padrão. $\mathrm{O}$ teste $\mathrm{t}$ de

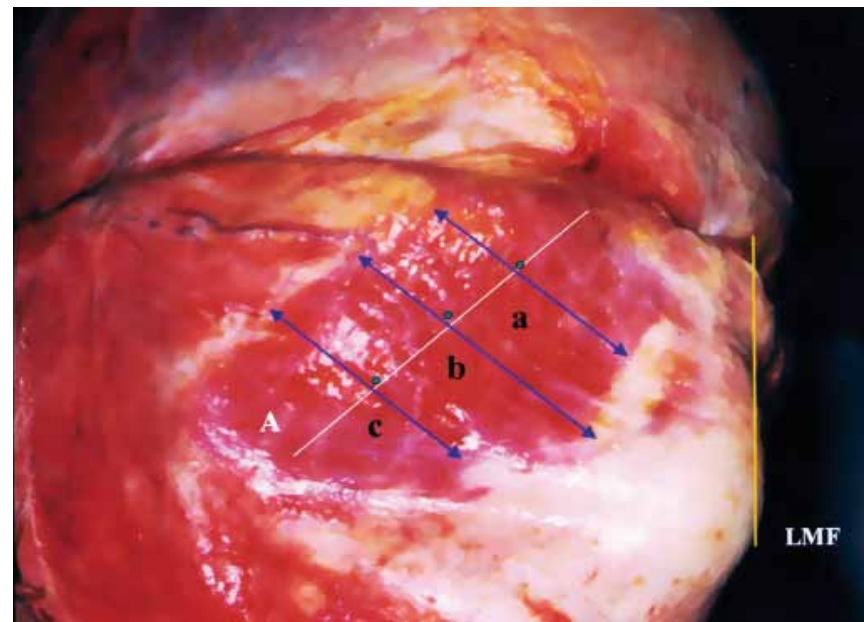

Figura 4 - Vista lateral: retalho frontal rebatido, linha médio-frontal demarcada (LMF), medições das larguras e espessuras ventrais a 1,5, 3,0 e 4,5 cm do ponto glabelar. Medidas as alturas ventrais.

Student foi empregado para análise de dados pareados e independentes.

1. Distâncias Interventrais - sexos masculino vs. feminino

- Distância Interventral a $1,5 \mathrm{~cm}$ : média de $0,5 \mathrm{~cm}$, no sexo masculino, e de $0,6 \mathrm{~cm}$, no feminino;

- Distância Interventral a 3,0 cm: média de $1,3 \mathrm{~cm}$, no sexo masculino, e de $1,7 \mathrm{~cm}$, no feminino.

- Distância Interventral a $4,5 \mathrm{~cm}$ : média de $3,4 \mathrm{~cm}$, no sexo masculino, e de $4,3 \mathrm{~cm}$, no feminino.

2. Distâncias Interventrais - raças branca vs. não-branca

- Distância Interventral a 1,5 cm: média de $0,5 \mathrm{~cm}$, na raça branca, e de 0,6 cm, na não-branca;

- Distância Interventral a 3,0 cm: média de 1,3 cm, na raça branca, e de 1,7 cm, na não-branca;

- Distância Interventral a 4,5 cm: média de 3,6 cm, na raça branca e de 3,9 cm, na não-branca.

3. Altura dos V. Frontais - sexos masculino vs. feminino (lados direito + esquerdo)

A altura média do ventre direito para os homens foi de $5,9 \mathrm{~cm}$, o esquerdo de $6 \mathrm{~cm}$, perfazendo média total de 6,0 $\mathrm{cm}$. Para as mulheres, a altura média do ventre direito foi de $5,8 \mathrm{~cm}$ e de $6,0 \mathrm{~cm}$ no lado esquerdo, com média de $5,9 \mathrm{~cm}$.

4. Altura dos V. Frontais - raças branca vs. não-branca (lados direito + esquerdo)

A altura média do ventre direito para a raça branca foi de $5,8 \mathrm{~cm}$, o esquerdo de $6 \mathrm{~cm}$, perfazendo média total de $5,9 \mathrm{~cm}$. Para a raça não-branca, a altura média foi de $6,0 \mathrm{~cm}$ para ambos os ventres, com média de $6,0 \mathrm{~cm}$. 
5. Larguras - sexo masculino vs. feminino (lados direito + esquerdo)

- Largura a 1,5 cm: para o sexo masculino foi de $6,2 \mathrm{~cm}$ no lado direito e $6,4 \mathrm{~cm}$ do lado esquerdo, com média de $6,3 \mathrm{~cm}$, e para feminino de $5,7 \mathrm{~cm}$ no lado direito e $5,6 \mathrm{~cm}$ no lado esquerdo, com média de $5,6 \mathrm{~cm}$;

- Largura a 3,0 cm: para o sexo masculino foi de $6 \mathrm{~cm}$ para ambos os lados, com média de $6 \mathrm{~cm}$, e para feminino de $5,3 \mathrm{~cm}$ também em ambos os lados, com média de 5,3 cm;

- Largura a 4,5 cm: para o sexo masculino foi de $4,4 \mathrm{~cm}$ no lado direito e $4,6 \mathrm{~cm}$ no lado esquerdo, com média de $4,5 \mathrm{~cm}$, e para feminino de $3,1 \mathrm{e} 3,7 \mathrm{~cm}$, respectivamente, à direita e à esquerda, com média de $3,4 \mathrm{~cm}$.

6. Larguras - raças branca vs. não-branca (lados direito + esquerdo)

- Largura a 1,5 cm: para a raça branca foi de $5,9 \mathrm{~cm}$ à direita e $6,0 \mathrm{~cm}$ à esquerda, com média de $6,0 \mathrm{~cm}$; na raça não-branca, encontramos 6,1 e $6,2 \mathrm{~cm}$, respectivamente, para os lados direito e esquerdo, com média de $6,2 \mathrm{~cm}$;

- Largura a 3,0 cm: para a raça branca foi de $5,6 \mathrm{~cm}$ à direita e $5,8 \mathrm{~cm}$ à esquerda, com média de $5,7 \mathrm{~cm}$; na raça não-branca, encontramos 5,8 e $5,7 \mathrm{~cm}$, respectivamente, para os lados direito e esquerdo, com média de $5,8 \mathrm{~cm}$;

- Largura a 4,5 cm: para a raça branca foi de $4,0 \mathrm{~cm}$ à direita e 4,4 cm à esquerda, com média de $4,2 \mathrm{~cm}$., na raça não-branca, encontramos 4,0 e $4,1 \mathrm{~cm}$, respectivamente, para os lados direito e esquerdo, com média de $4,0 \mathrm{~cm}$.

7. Espessuras - sexo masculino vs. feminino (ventres direito + esquerdo)

- Espessura a 1,5 cm: para o sexo masculino foi de 1,2 $\mathrm{mm}$ à direita e $1,1 \mathrm{~mm}$ à esquerda, e para o sexo feminino

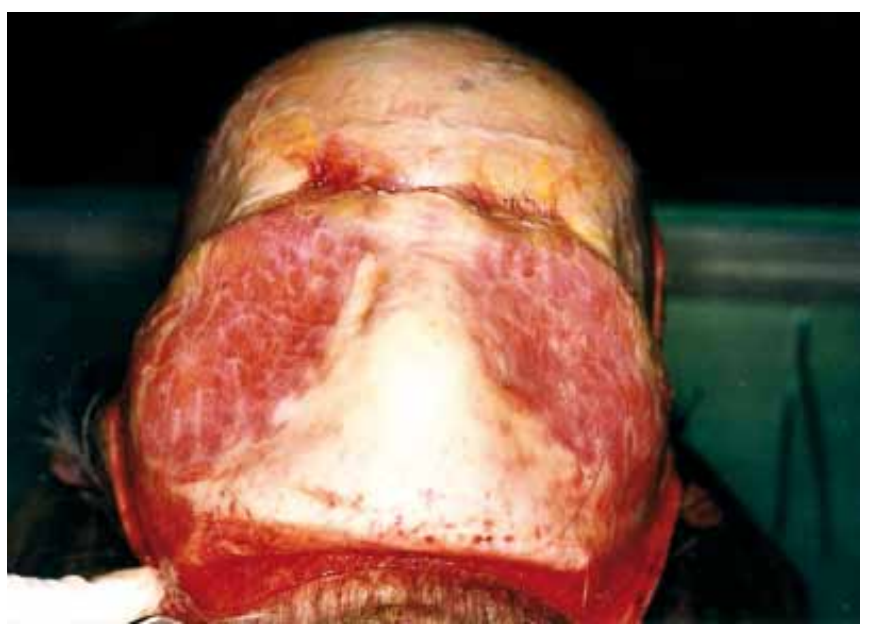

Figura 5 - Tipo I (vista anterior): retalho frontal rebatido, demonstrando a separação completa dos ventres frontais. de $1,1 \mathrm{~mm}$ em ambos os lados, perfazendo uma média de $1,1 \mathrm{~mm}$ nos dois sexos;

- Espessura a 3,0 cm: para o sexo masculino foi de 1,2 $\mathrm{mm}$ nos dois lados, com média de $1,2 \mathrm{~mm}$, e para o sexo feminino, de $1,2 \mathrm{~mm}$ no lado direito e $1,1 \mathrm{~mm}$ no esquerdo, com média de $1,1 \mathrm{~mm}$;

- Espessura a 4,5 cm: para o sexo masculino foi de 1,3 $\mathrm{mm}$ no lado direito e $1,1 \mathrm{~mm}$ no esquerdo, com média de $1,2 \mathrm{~mm}$, e para o sexo feminino de $1 \mathrm{~mm}$ nos dois lados, com média de $1 \mathrm{~mm}$.

8. Espessuras - raças branca vs. não branca (ventres direito + esquerdo)

- Espessura a 1,5 cm: para raça branca foi de $1,1 \mathrm{~mm}$ em ambos os lados, com média de $1,1 \mathrm{~mm}$, e para não-branca de $1,3 \mathrm{~mm}$ no lado direito e $1,0 \mathrm{~mm}$ no esquerdo, com média de $1,2 \mathrm{~mm}$;

- Espessura a 3,0 cm: para raça branca foi de 1,2 $\mathrm{mm}$ em ambos os lados, com média de $1,2 \mathrm{~mm}$, e para não-branca de $1,3 \mathrm{~mm}$ no lado direito e $1,1 \mathrm{~mm}$ no esquerdo, com média de $1,2 \mathrm{~mm}$;

- Espessura a 4,5 cm: para raça branca foi de 1,2 $\mathrm{mm}$ no lado direito e $1,1 \mathrm{~mm}$ no esquerdo com média de 1,2 $\mathrm{mm}$, e para não-branca de $1,1 \mathrm{~mm}$ no lado direito e 1,0 $\mathrm{mm}$ no esquerdo, com média de $1,0 \mathrm{~mm}$.

Os ventres frontais apresentaram-se de maneiras diferentes, principalmente quanto à disposição das fibras mediais, sendo agrupados em 4 tipos, conforme os critérios abaixo:

- Tipo I - Os ventres estão totalmente separados a $1,5 \mathrm{~cm}$ da glabela (Figuras 5 e 6 );

- Tipo II - Os ventres estão unidos a $1,5 \mathrm{~cm}$ da glabela (Figuras 7 e 8);

- Tipo III - Os ventres estão unidos a 3,0 cm da glabela (Figuras 9 e 10);

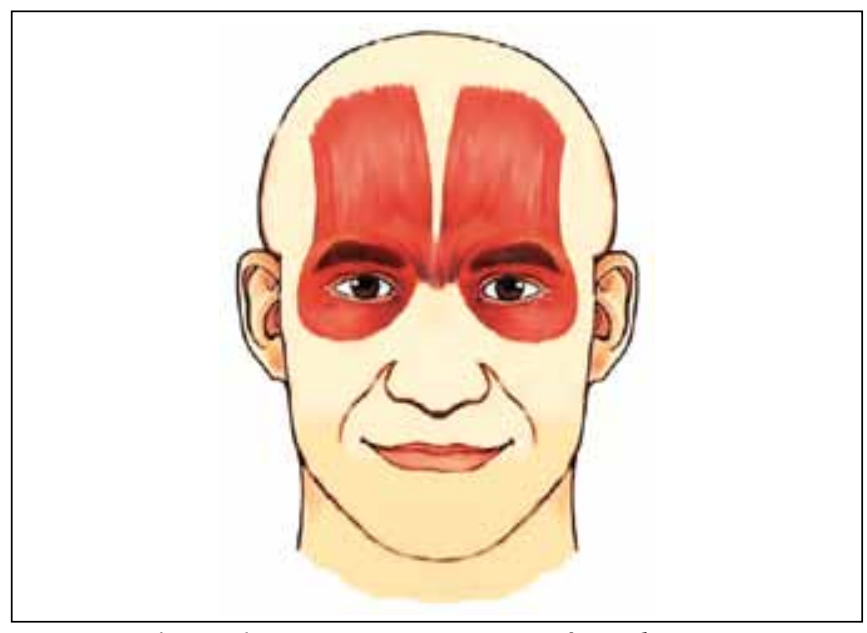

Figura 6 - Representação esquemática do tipo I. 


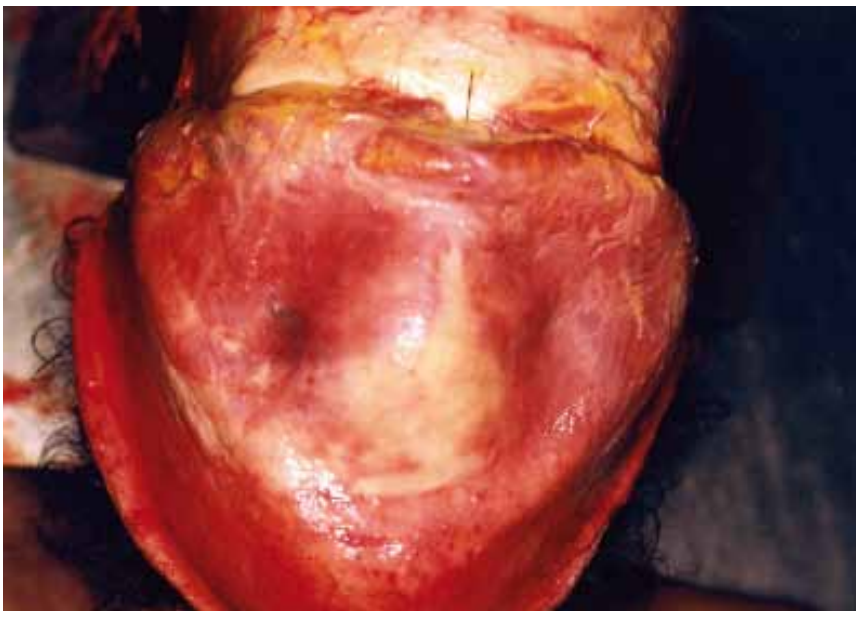

Figura 7 - Tipo II (vista anterior): retalho frontal rebatido, demonstrando a união dos ventres frontais a 1,5 cm da glabela.

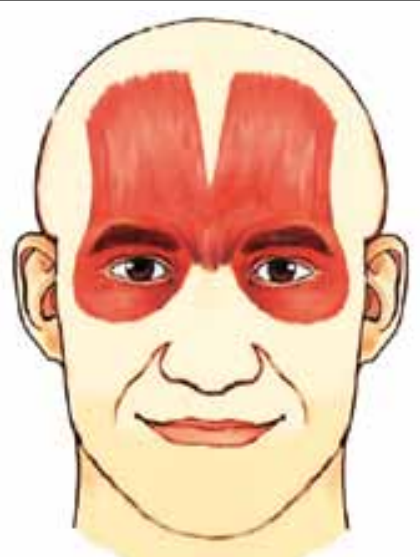

Figura 8 - Representação esquemática tipo II.

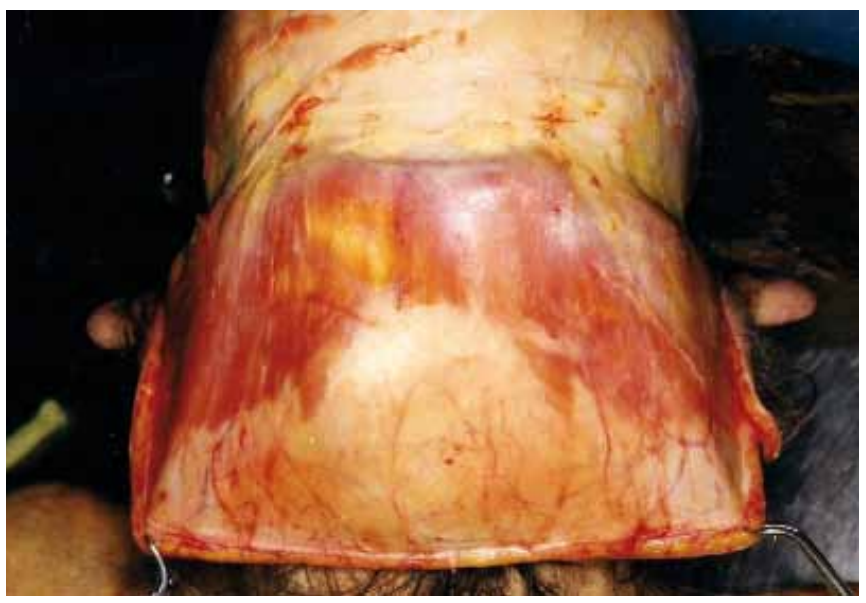

Figura 9 - Tipo III (vista anterior): retalho frontal rebatido, demonstrando a união dos ventres frontais a $3,0 \mathrm{~cm}$ da glabela.

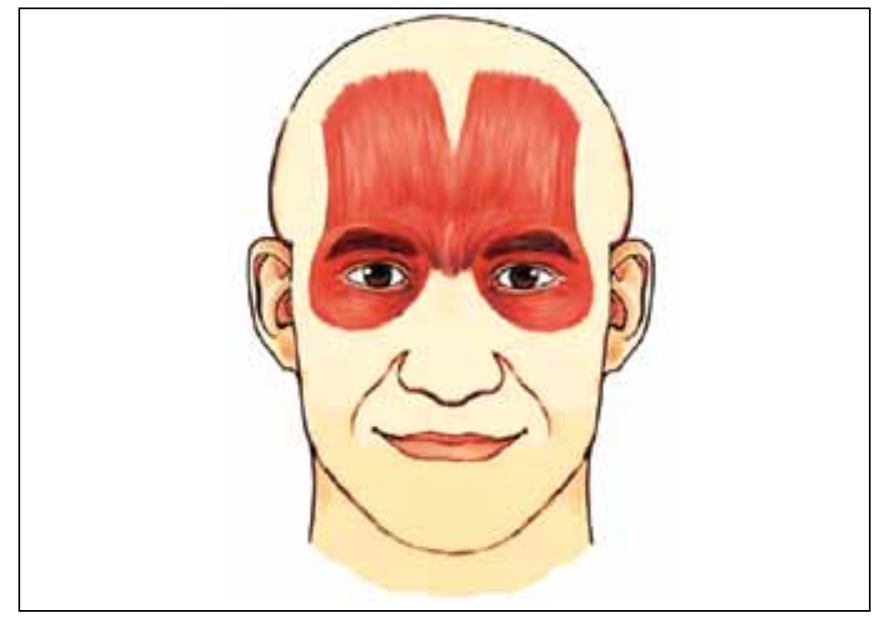

Figura 10 - Representação esquemática tipo III.

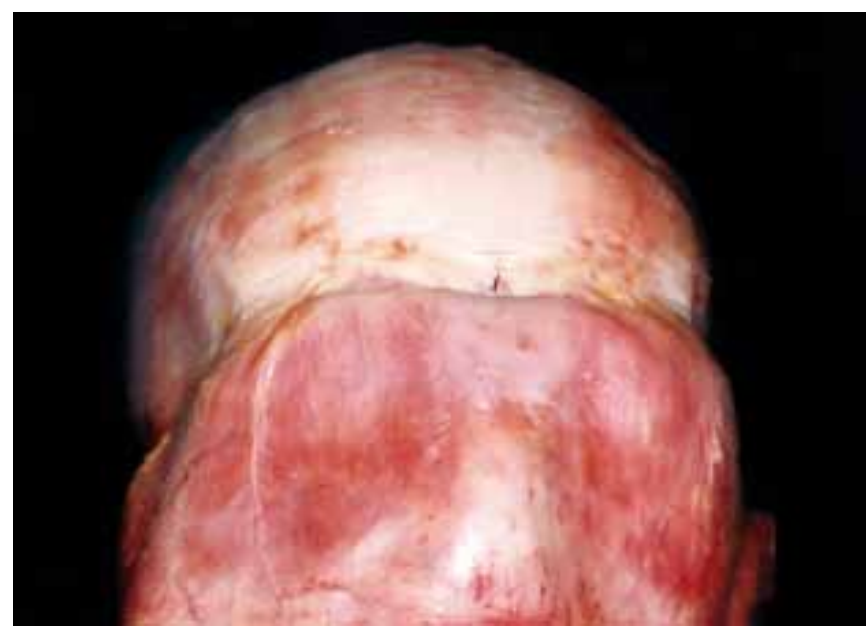

Figura 11 - Tipo IV (vista anterior): retalho frontal rebatido, demonstrando a união dos ventres frontais a $4,5 \mathrm{~cm}$ da glabela.

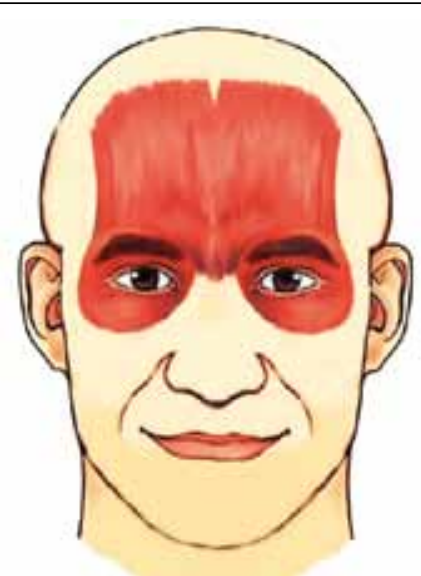

Figura 12 - Representação esquemática tipo IV. 
- Tipo IV - Os ventres estão unidos a 4,5 cm da glabela (Figuras 11 e 12).

O tipo I englobou $39,5 \%$ da população total estudada, o tipo II correspondeu a $30,5 \%$, o tipo III a $21,6 \%$ e o tipo IV a $8,5 \%$ (Figura 13).

$\mathrm{O}$ teste $\mathrm{t}$ de Student para dados independentes não demonstrou diferenças estatisticamente significantes entre os sexos ou raças, no parâmetro distância interventral, nos três pontos analisados. $\mathrm{O}$ aumento destas distâncias demonstra que os ventres tenderam a afastar-se da linha médio frontal, conforme se caminha em direção superior, tomando uma posição oblíqua na fronte.

$\mathrm{O}$ teste $\mathrm{t}$ de Student para dados pareados e independentes não demonstrou diferenças significantes, nem entre os lados ventrais nem entre os sexos, ou mesmo entre as raças, no parâmetro alturas frontais.

O teste $t$ de Student para dados pareados mostrou que a $4,5 \mathrm{~cm}$ da glabela, na raça branca, o lado direito mostrou-se maior que o esquerdo. $\mathrm{O}$ mesmo teste para dados independentes não apresentou diferenças nas larguras entre as raças, porém todas as medidas de largura, no sexo masculino, foram maiores que no feminino.

$\mathrm{O}$ teste $\mathrm{t}$ de Student para dados pareados não demonstrou diferenças estatísticas entre os lados direito e esquerdo quanto às raças em relação à espessura, porém notou-se que a $4,5 \mathrm{~cm}$ da glabela, no sexo masculino, a espessura direita foi maior que a esquerda. Para dados independentes não houve diferença entre as raças, entretanto, o sexo masculino apresentou maior espessura a $4,5 \mathrm{~cm}$ da glabela em relação ao feminino.

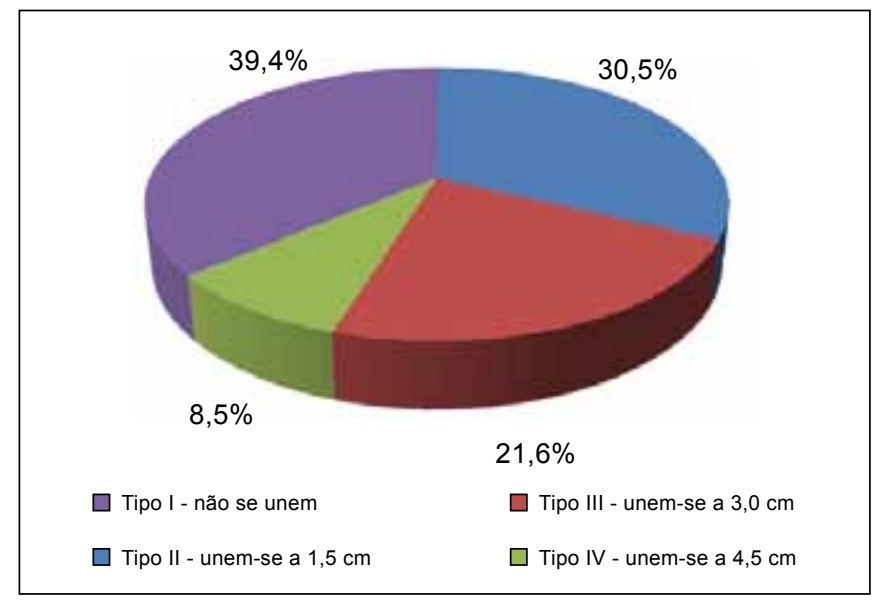

Figura 13 - Distribuição dos tipos de ventres frontais quanto à posição das fibras mediais na população total estudada.

\section{DISCUSSÃO}

Apesar da grande importância dos ventres frontais do músculo occipitofrontal, seu estudo morfológico, sua disposição espacial na fronte e, principalmente, suas diferentes formas de apresentação não foram completamente descritas.

Não encontramos na literatura a abordagem dos parâmetros citados, em artigos que descrevam a anatomia local associada ou não a procedimentos cirúrgicos, ou em compêndios de anatomia.

Testut anota em seu tratado algumas variações dos ventres frontais, como inserções anteriores na região supraorbitária ou apófise orbitária externa. Cita ainda os trabalhos de Macalister, que notou prolongamentos dos frontais até mesmo entre os músculos elevadores das asas nasais e lábio superior.

Em outra obra sua que versa exclusivamente sobre as variações musculares no homem, Testut refere-se a anatomistas como Wood, que já em 1873 concluía que as variações musculares são muito frequentes, e enumerava as possíveis causas de disposições musculares incomuns, entretanto não se referiu em nenhum instante aos ventres frontais.

Diferentemente da ideia na qual os frontais constituem uma "placa" muscular contínua ocupando toda a largura da região frontal $l^{9}$, na maioria dos cadáveres dissecados, os ventres apresentaram-se separados e afastando-se cada vez mais da linha médio-frontal em direção superior.

Dentre os trabalhos mais recentes pesquisados, Soares et al. ${ }^{10}$ citam e dividem de forma bastante interessante as variações frontais, porém não as detalham morfologicamente. Connell et al. ${ }^{11}$, em um artigo sobre como evitar complicações em ritidoplastias, alertaram para as variações de forma e posição dos ventres frontais, notada durante atos cirúrgicos.

Ressaltamos que, apesar dos valores obtidos nos darem uma posição média da disposição morfológica dos ventres frontais na população geral, notamos disparidades importantes, como alturas ventrais variando de 3,2 a 8,4 $\mathrm{cm}$, apesar de termos uma média geral de $5,9 \mathrm{~cm}$. Tal fato ocorreu também quanto às larguras ventrais, cujos valores variaram de 3,0 a $8,7 \mathrm{~cm}$, conforme a distância do ponto glabelar.

\section{CONCLUSÕES}

O amplo conhecimento anatômico nos permite um planejamento pré-operatório mais seguro. Ao programar 
um retalho utilizando os frontais para os diferentes propósitos, ou em cirurgias que visem à diminuição da ação muscular, ou ainda o uso de substâncias injetáveis para atenuação desta função, todas as possibilidades de posição devem ser levadas em consideração para um resultado satisfatório.

\section{REFERÊNCIAS}

1. Nomina Anatomica. 5th ed. Baltimore:Willians \& Wilkins;1983.

2. Spalteholz-Spanner. Atlas de anatomia humana. São Paulo:Rocca;1985. $\mathrm{I}: 334$

3. Testut L. Anatomie humaine. 7 ed. Paris:Gaston Doin;1921. I:729.

4. Chiarugi G. Instituzioni di anatomia dell'uomo. $4^{\mathrm{a}}$ ed. Vol. $2^{\circ}$. Milano:Soc. Ed. Livraria;1936.
5. Tandler J. Tratado de anatomia sistemática. Barcelona: Salvat; 1928. I:32.

6. Gray H. Anatomia. 29a ed. Rio de Janeiro: Guanabara Koogan; 1988. p.312-3.

7. Fatah MF. Innervation and functional reconstruction of the forehead. Br J Plast Surg. 1991;44(5):351-8.

8. Edwards BF. Bilateral temporal neurotomy for frontalis hypermotility; case report. Plast Reconstr Surg. 1957;19(4):341-5.

9. Testut L. Les anomalies musculaires chez 1'homme. G. Paris:Masson;1884. p.761-81

10. Soares RT, Cheffe LO, Alvarez AC. Variantes anatômicas do músculo frontal e sua importância em cirurgia plástica. In: Anais da $1^{\text {a Jornada }}$ Sul Brasileira de Cirurgia Plástica. Florianópolis, Brasil: Artgraf; 1984. p.25.

11. Connell BF, Lambros VS, Neurohr GH. The forehead lift: techniques to avoid complications and produce optimal results. Aesthetic Plast Surg. 1989;13(4):217-37.

\section{Correspondência para:}

Norton Glattstein

Rua Dr. Amâncio de Carvalho, 399 - São Paulo, SP, Brasil - CEP 04012-090

E-mail: cliesc@terra.com.br 